\title{
The use of Chlorella vulgaris to accumulate magnesium under different culture conditions
}

\begin{abstract}
We investigated magnesium $\left(\mathrm{Mg}^{2+}\right)$ ion uptake by Chlorella vulgaris under mixotrophic growth conditions $(10 \mathrm{~g} / \mathrm{L}$ of glucose) in a stirred photo-bioreactor. The culture nitrate and glucose consumptions were followed and analyzed during the experiments. The cellular chlorophyll $\alpha$ concentration decreased during exponential growth, indicating an adaptation to heterotrophic metabolism. The partition of magnesium partitioned between the culture medium, the cell surface and within the cells was determined throughout the experiment. A clear relationship between the microalgal concentration and $\mathrm{Mg}^{2+}$ ion removal-extent from the medium was observed. The removal rate was faster during mixotrophic growth than autotrophic growth and was related to the higher biomass production under the latter culture conditions. The $\mathrm{Mg}^{2+}$ concentration per gram of dry biomass was $3.44 \mathrm{mg} / \mathrm{g}$ under heterotrophic conditions and $6.0 \mathrm{mg} / \mathrm{g}$ under autotrophic growth. At the end of the experiment $(330 \mathrm{~h}), 90 \%$ of the initial magnesium $(17.7 \mathrm{mg} / \mathrm{L})$ in the medium was associated with the biomass, of which $4 \%$ was adsorbed and $86 \%$ absorbed by cells. This study was consistent with the kinetic model based on a reversible first-order reaction for $\mathrm{Mg}^{2+}$ bioaccumulation in C. vulgaris. Mixotrophic growth conditions can be used at industrial scale to increase both the speed and the extent of $\mathrm{Mg}^{2+}$ uptake by the microalgal..
\end{abstract}

Volume 2 Issue 5 - 2017

\author{
Ben Amor-Ben Ayed H,' Taidi B, ' Ayadi $\mathrm{H}^{2}{ }^{2}$ \\ Pareau D,' Stambouli M' \\ 'Process Engineering and materials Lab, France \\ ${ }^{2}$ Department of Planktonology, University of Sfax, Tunisia
}

\begin{abstract}
Correspondence: Hela Ben Amor-Ben Ayed, Process Engineering and materials Lab, Centrale Supélec, Grande Voie des Vignes, 92295 Châtenay-Malabry, France, Tel +33695246886,
\end{abstract} Email helabenamor09@yahoo.fr

Received: November 04, 2016 | Published: March 24, 2017

Keywords: chlorella vulgaris, mixotrophy, magnesium, intracellular absorption, extracellular adsorption Abbreviations: $\mathrm{Mg}^{2+}$, magnesium; $\mathrm{NO}_{3}^{-}$, nitrate; $\mathrm{A}_{800}$, absor-
bance measured at a wavelength of $800 \mathrm{~nm}$

\section{Introduction}

The autotrophic green microalgae $C$. vulgaris can grow heterotrophically if presented with a suitable organic carbon source ${ }^{1-3}$ or mixotrophically by simultaneous autotrophic and heterotrophic metabolisms. ${ }^{2,4}$ C. vulgaris can use a number of organic carbon sources such as glucose or acetic acid. Glucose and other organic substrates can stimulate the growth of this alga in the presence or the absence of light. ${ }^{5-7}$ Microalgae cultures offer a wide industrial application due to their ability to assimilate metals. ${ }^{8,9}$ The intended application of this study is to enrich $C$. vulgaris with magnesium for cosmetic purposes. We have previously reported that $C$. vulgaris is not inhibited by up to $500 \mathrm{mg} / \mathrm{L} \mathrm{Mg}^{2+}$ ions and that the alga could accumulate a relatively large amount of $\mathrm{Mg}^{2+} \cdot{ }^{10,11}$ This metal is essential for photosynthesis as it occupies the core of the chlorophyll molecule and influences the activity of various photosynthetic enzymes. ${ }^{12}$ The large $\mathrm{Mg}^{2+}$ accumulation amount renders $C$. vulgaris of industrial interest for the recovery/elimination of useful metals such as magnesium from aqueous media. One aim of this study was to examine the way in which C. vulgaris grew under mixotrophic growth conditions by providing it simultaneously with two carbon and energy sources; light, $\mathrm{CO}_{2}$ and glucose. A second aim was to investigate the magnesium accumulation (extracellular and intracellular) under these conditions and to further investigate the validity of the previously reported model for the $\mathrm{Mg}^{2+}$ biomass-association under autotrophic conditions. ${ }^{10}$

\section{Materials and methods}

\section{Microorganism and growth medium}

The strain Chlorella vulgaris CCAP211/e 11B (trebouxiophyceae) was obtained from the Culture Collection of Algae and Protozoa, CCAP (UK). The growth medium used was the modified 3N-Bristol medium, ${ }^{13,14}$ in which the sole nitrogen source is nitrate at a concentration of $547.03 \mathrm{mg} / \mathrm{L}$. The glucose concentration of $10 \mathrm{~g} / \mathrm{L}$ was added to the medium prior to sterilization. The base $\mathrm{Mg}^{2+}$ ion concentration was enriched to approximately $18 \mathrm{mg} / \mathrm{L}$ in order to compare with previous autotrophic culture of $C$. vulgaris at the same $\mathrm{Mg}^{2+}$ concentration. ${ }^{11}$

\section{Bioreactor cultures}

C. vulgaris was grown in a cylindrical stirred tank "Biostat B plus" bioreactor (5L working volume; Sartorius, Germany). Stirring (750rpm) was provided by a three palettes (UniVessel 5L), each inclined at $45^{\circ} \mathrm{C}$ from the horizontal axis (pitch blade stirrer) (Figure 1). The total light intensity at the inner surface of the bioreactor was measured (LI250A, LI-COR, USA) at $2900 \mu \mathrm{mol} / \mathrm{m}^{2} . \mathrm{s}$ achieved by 6 LED lamps (IKEA LEDARE, 2700 Kelvin, $27^{\circ} \mathrm{C}$ dispersion angle, France). The culture temperature was maintained at $25^{\circ} \mathrm{C}$ by circulating water through a jacketed vessel (Figure1). Continuous aeration with sterile air $(0.2 \mu \mathrm{m}$ Sartorius gas filter) at $500 \mathrm{ml}$ air/ $\min \left(1 \mathrm{~atm} .25^{\circ} \mathrm{C}\right)$ was used to supply both oxygen and $\mathrm{CO}_{2}$ to the culture. The inlet and outlet airflow rates were measured daily. The sterile medium was inoculated with a shake-flask $(50 \mathrm{ml}$ in $250 \mathrm{ml}$ flask) culture of $C$. vulgaris at the end exponential growth (72-96h). The inoculum volume constituted $1 \%(\mathrm{v} / \mathrm{v})$ of the bioreactor working volume (5L), which gave a cell concentration of $2 \times 10^{6}$ cells $/ \mathrm{ml}$ at the beginning of the experiment. The inoculum was prepared in the same medium as that used in the bioreactor (MBM medium containing $10 \mathrm{~g} / \mathrm{L}$ of glucose).

\section{Analytical techniques}

Growth measurement: Three methods were used to measure the 
biomass concentration: absorbance at $800 \mathrm{~nm}$; cell count; dry weight biomass concentration. The cell number per liquid volume was determined by counting the cells using a microscope (Carl Zeiss axioplan imaging 2, Germany) and a Thomas counting chamber of $0.1 \mathrm{~mm}$ depth. The absorbance $\left(\mathrm{A}_{800}\right)$ of the algal cultures was measured at 800nm (Spectrophotometer Cary 300 Scan UV-visible, Varian Inc, Netherlands) after appropriate dilution. The cell viability was measured using a GUAVA easyCyte ${ }^{\mathrm{TM}}$ flow cytometer (Merck Millipore, France) with the ViaCount (14-0155) method. The dry weight (DW) biomass concentration $(\mathrm{g} / \mathrm{L})$ was determined by the following method. The culture sample was first centrifuged (10minutes, 1800g) The pellet was washed through re-suspension in an equal volume of deionized water and centrifuged again $(10$ minutes, $1800 \mathrm{~g})$. The resulting pellet was transferred into a dry pre-weighted ceramic thimble and heated $\left(24 \mathrm{~h}, 105^{\circ} \mathrm{C}\right)$ in an oven. After drying, the thimble was weighed. In order to follow the growth rate, three samples (10-15ml) were removed daily from the bioreactor during the exponential growth phase $(0-74 \mathrm{~h})$ and only one sample a day was analysed in the other growth phases.

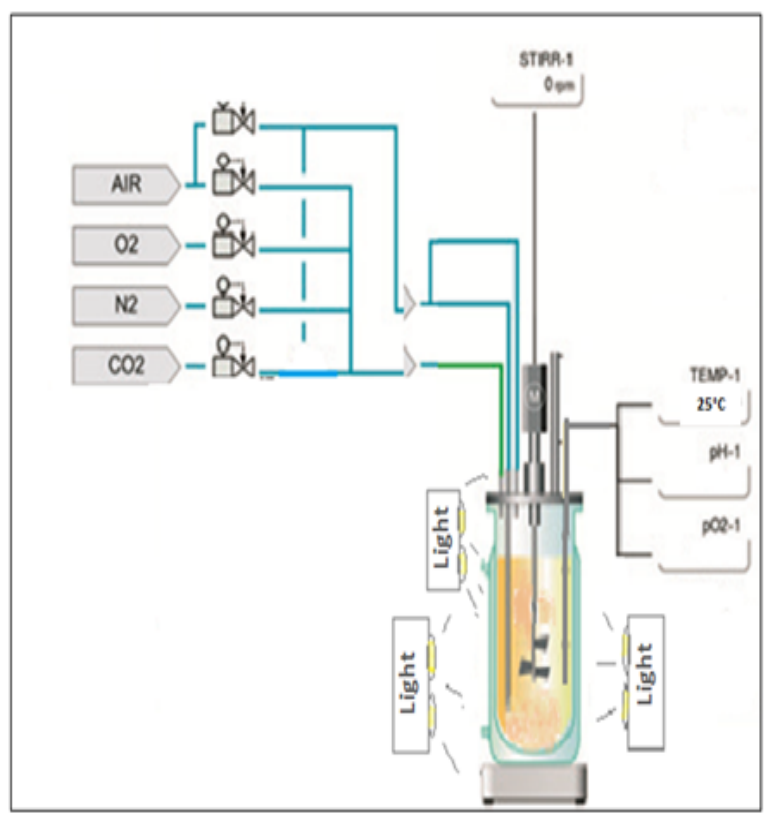

Figure I Bioreactor "Biostat B plus".

Determination of the glucose concentration: Glucose consumption was followed by measuring glucose concentration in the culture medium (supernatant) obtained from all the samples. This measurement was performed with a High-Performance Liquid Chromatography (HPLC) (Ultimate 3000, column: HPX-87H). A total pressure of approximately $870 \mathrm{psi}$ at $45^{\circ} \mathrm{C}$ was applied. The eluent was sulphuric acid $(2 \mathrm{~mm})$. All samples were first filtered through $0.2 \mu \mathrm{m}$ and $\mathrm{C} 18$ columns to retain all particles and proteins that could influence the HPLC analysis.

Determination of the nitrate concentration: $\mathrm{The}^{\mathrm{NO}_{3}}{ }_{3}^{-}$analyses were performed by ionic chromatography using a Dionex AS11-HC column installed in a Class 10.000 clean room under the following conditions: system Dionex DX-500, column (CR-ATC, P/N 060477) $(4 \mathrm{~mm})$ with a guard column AG11-HC and a total pressure of 2.300 psi at $30^{\circ} \mathrm{C}$, conductimetric detector $\mathrm{CD} 20$. The eluent $(\mathrm{KOH})$ concentration was $30 \mathrm{mmol} / \mathrm{L}$ at $1.5 \mathrm{ml} / \mathrm{min}$.
Determination of the chlorophyll concentration: Triplicate samples were removed daily from the bioreactor in order to extract and calculate the cellular chlorophyll $\alpha$ concentration during the experiment according to method of Porra. ${ }^{15}$

Determination of the magnesium ion concentration: An Atomic Absorption Spectrophotometer (Hitachi Z-2300, Japan) was used in order to measure the $\mathrm{Mg}^{2+}$ ion concentration using an air-acetylene flame and by measuring the absorbance at a wavelength of $202.6 \mathrm{~nm}$ with the specific magnesium lamp (Agilent technologies, France). The standard deviations for the calibration curve $(0.15$ to $20.0 \mathrm{mg} / \mathrm{L})$ were in the range 1 to $2 \%$. The sample dilutions were carried out with Milli-Q water acidified with $\mathrm{HCL}(\mathrm{pH}<3)$ to prevent metal precipitation. The calibration solutions were prepared from $1000 \mathrm{mg} / \mathrm{L}$ magnesium stock solution (Fischer scientific) and measured 5 times in order to determine the precision of the analysis.

Estimation of adsorbed and absorbed magnesium concentrations: The concentrations of adsorbed (extracellular) and absorbed (intracellular) magnesium were determined by the procedure described by Franklin et al. ${ }^{16}$ and Ma et al. ${ }^{17}$ with minor modifications as published in our previous work. ${ }^{10}$

Magnesium bioaccumulation modeling: A reversible reaction of first order with respect to the magnesium concentration in the culture liquid was assumed for $\mathrm{Mg}^{2+}$ ions uptake by cells. This model has been already published with all details. ${ }^{16}$ The model is given by the following Equation (1):

$$
\frac{C(t)-C_{e q}}{C_{0}-C_{e q}}=e^{-k \alpha t}
$$

Equation (1)

Where k.a is the kinetic constant, the concentrations $\mathrm{C}, \mathrm{C}_{0}$ and $\mathrm{C}_{\mathrm{eq}}$ are the $\mathrm{Mg}^{2+}$ ion concentrations at times: $\mathrm{t}, \mathrm{t}_{0}$ and at equilibrium respectively $(\mathrm{mg} / \mathrm{L})$.

\section{Results and discussion}

\section{Algal growth characteristics in a stirred photo-bio- reactor}

C. vulgaris was grown independently and in duplicate in stirred photo-bioreactor cultures under mixotrophic conditions in order to investigate magnesium accumulation. Each experiment lasted 310h. The initial glucose and $\mathrm{Mg}^{2+}$ ion concentrations were $10 \mathrm{~g} / \mathrm{L}$ and $17.7 \mathrm{mg} / \mathrm{L}$ in medium, respectively. The absorbance $A_{800}$, the cell concentration $\mathrm{Nb}$ (number of cells $/ \mathrm{ml}$ ) and the dry weight concentration DW $(\mathrm{g} / \mathrm{L})$ were measured daily except during the exponential growth phase where they were measure three times per day. These three growth parameters showed a satisfying degree of proportionality for the duplicate experiments (Figure 2), and confirmed the results of Rocha et al. ${ }^{18}$ "Corrected absorbance" refers to the absorbance measured with diluted samples and multiplied by the dilution factor. The following correlations were obtained:

$$
\begin{aligned}
& \mathrm{A}_{800}=\left(3.3 \times 10^{-8}\right) \mathrm{Nb}(\text { cells } / \mathrm{ml}) \text { and } \\
& \text { DW }(\mathrm{g} / \mathrm{L})=\left(1.0 \times 10^{-8}\right) \mathrm{Nb}(\text { cells } / \mathrm{ml}) .
\end{aligned}
$$

The dry weight of an average individual C. vulgaris cell was calculated and found to remain constant at $1.0 \times 10^{-11} \mathrm{~g}$ throughout the experiments, which corresponds to published values for this algal. ${ }^{19}$ 
Cell viability remained at $96 \pm 2 \%$ throughout the experiments. The growth curves under both autotrophic $(765 \mathrm{~h})$ and mixotrophic (310h) culture conditions are presented in the same Figure 3. The specific growth rate $(\mu)$ for the culture was determined from the absorbance data during the exponential growth phase at $0.056 \mathrm{~h}^{-1}$ according to the method of Wood et al. ${ }^{20}$ The $\mu$ value was relatively close to the published values $\left(\mu=0.06 \mathrm{~h}^{-1}\right.$; Perner Nochta et al. $\left.{ }^{21}\right)$ for the same organism in a batch cultures in tubular bioreactor. The cell concentration after $310 \mathrm{~h}$ of culture was higher $\left(\mathrm{A}_{800}=23\right.$ corresponding to $8.8 \times 10^{8} \mathrm{cells} / \mathrm{ml}$ ) in mixotrophic growth conditions than the biomass concentration obtained $\left(\mathrm{A}_{800}=5\right.$ corresponding to $\left.1 \times 10^{8} \mathrm{cells} / \mathrm{ml}\right)$ after $765 \mathrm{~h}$ of autotrophic culture in the photo-bioreactor (Figure 3). These results are in good agreement with Lee et al. ${ }^{22}$ which investigated the mixotrophic growth (glucose $18 \mathrm{~g} / \mathrm{L}$ ) of Chlorella sorokiniana) and reported a higher cell concentration compared to autotrophic growth. For mixotrophic culture conditions, glucose and nitrate $\left(\mathrm{NO}_{3}^{-}\right.$ ) concentrations were measured (Figure 4).

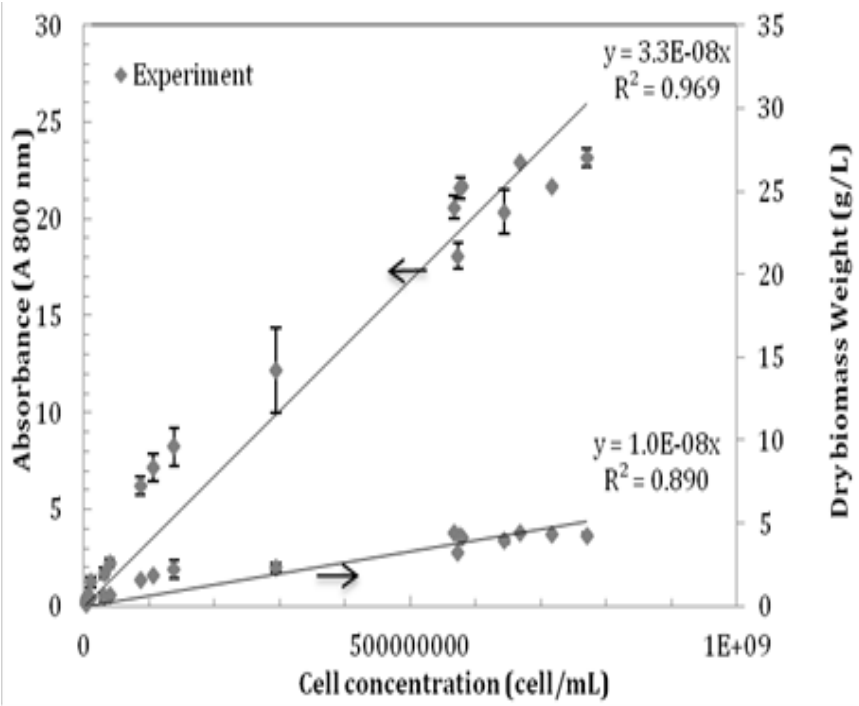

Figure 2 The relationships between the different measurement methods of C. vulgaris biomass: corrected absorbance and dry weight concentration were plotted against cell concentration. The standard deviations of measurements for both experiments are presented with error bars.

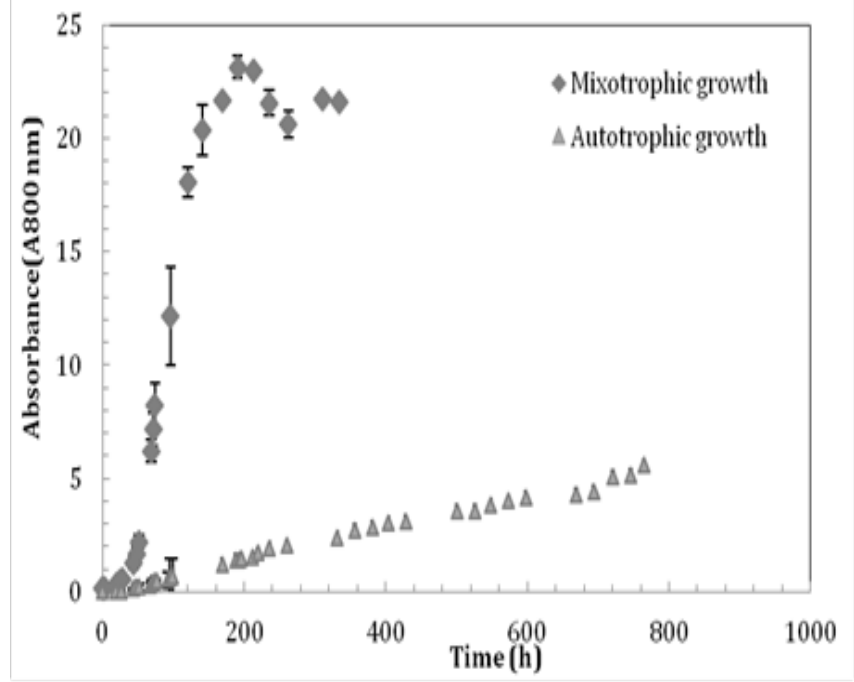

Figure 3 Growth curves for both experiments under mixotrophic and autotrophic growth ${ }^{17}$ conditions. Corrected absorbance versus time of incubation.

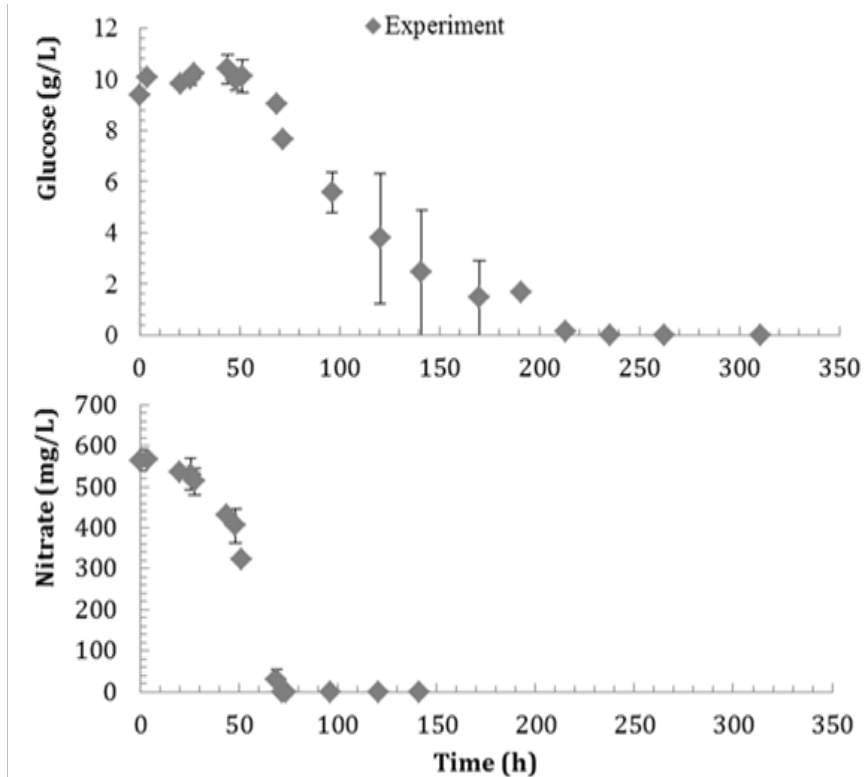

Figure 4 Glucose and nitrate concentrations profiles during C. vulgaris growth. The standard deviation of measurements is presented in the Figure with error bars.

Figure 4 shows that no significant consumption of glucose was observed during the exponential growth phase; this demonstrates autotrophic growth during this growth phase. The end of the exponential growth phase coincided with nitrate exhaustion, suggesting a limitation of growth by nitrogen. Three growth phases can be observed: exponential, transition and stationary phases. During the transition phase, glucose was rapidly removed from the growth medium suggesting mixotrophic growth. The exhaustion of glucose corresponded approximately to the start of the stationary phase as the cell concentration became stable. C. vulgaris exhibited a preference for autotrophic growth as long as nitrogen was available but after complete nitrogen exhaustion, glucose consumption occurred. There were slight differences in glucose consumption and cell growth between the duplicate experiments during the transition phase; elsewhere the repeatability between the experiments was very high. The average cellular chlorophyll $\alpha$ content (mg chlorophyll $\alpha$ per $g$ DW) decreased sharply during the exponential phase and remained approximately constant at a low value afterwards (Figure 5). This could be explained firstly by the decreasing of nitrates concentration in the medium that influence the chlorophyll production and secondly by the change of cell physiology upon glucose metabolism. This behavior was also observed by Illman et al. ${ }^{23}$ and $\mathrm{Li}$ et al. ${ }^{24}$ for the same microorganism in mixotrophic cultures. In this study, after exponential growth, the cellular chlorophyll content decreased to a constant value of $5 \times 10^{-11} \mathrm{mg} / \mathrm{cell}$. According to Kong et al. ${ }^{25}$ a high glucose concentration $(>5 \mathrm{~g} / \mathrm{L})$ inhibited chlorophyll production.

\section{Dissolved $\mathrm{Mg}^{2+}$ ion concentration}

The dissolved and biomass-associated $\mathrm{Mg}^{2+}$ ion concentrations (adsorbed and absorbed) were measured early on (74h), in the middle $(170 \mathrm{~h})$ and at the end $(310 \mathrm{~h})$ of the experiment. Each measurement was performed in triplicate. From the dissolved $\mathrm{Mg}^{2+}$ ion concentration the removal yield from the growth medium was calculated $\frac{\left(C_{0}-C\right)}{C_{0}}$ and plotted against the time of culture (Figure 6). A relationship emerged between $\mathrm{Mg}^{2+}$ ion removal from the medium and the biomass growth. 
Magnesium removal continued even after the end of the exponential phase until almost total removal (Figure 6). $\mathrm{Mg}^{2+}$ ion uptake continued during the heterotrophic growth phase; the uptake of this ion did not seem to be only related to chlorophyll synthesis. $\mathrm{Mg}^{2+}$ ion is also implicated in the activation of glycolytic enzymes for glucose metabolism. ${ }^{26}$

\section{Biomass associated magnesium ions}

The adsorbed and absorbed (extracellular and intracellular) $\mathrm{Mg}^{2+}$ ion increased during the experiment (Figure 7), the amount of absorbed
$\mathrm{Mg}^{2+}$ ion was always greater than the amount that was adsorbed. By the end of the experiment (310h), $90 \%$ of the initial $\mathrm{Mg}^{2+}$ ion content $(17.7 \mathrm{mg} / \mathrm{L})$ of the medium had been taken up by $C$. vulgaris, of which $4 \%$ of the total $\mathrm{Mg}^{2+}$ ions had been adsorbed on the cell wall and $86 \%$ had been absorbed into the cells. The calculated magnesium mass balances accounted for $97 \pm 2.0 \%$ of the initial amounts of the ion (Figure7). The calculation of the proportions of magnesium associated with biomass (adsorbed and absorbed) compared to the initial concentration added in the medium is subtracted from the mass balance as follows:

$$
(M g)_{\text {initial }}=(M g)_{\text {supernatant }}+(M g)_{\text {intracellular }}+(M g)_{\text {extracellular }}+(M g)_{\text {samples }}
$$

$(\mathrm{Mg})_{\text {initial }}$ : The initial magnesium concentration added in the culture medium.

$(\mathrm{Mg})_{\text {supernatant }}$ : The magnesium concentration dissolved in the medium and not captured by biomass.

$(\mathrm{Mg})_{\text {intracellular : }}$ The magnesium concentration absorbed into the microalgal cells.

$(\mathrm{Mg})_{\text {extracellular }}$ The magnesium concentration adsorbed on the cells walls.

$(\mathrm{Mg})_{\text {samples: }}$ The magnesium concentration of the samples removed from the culture. All magnesium concentration were expressed in mg

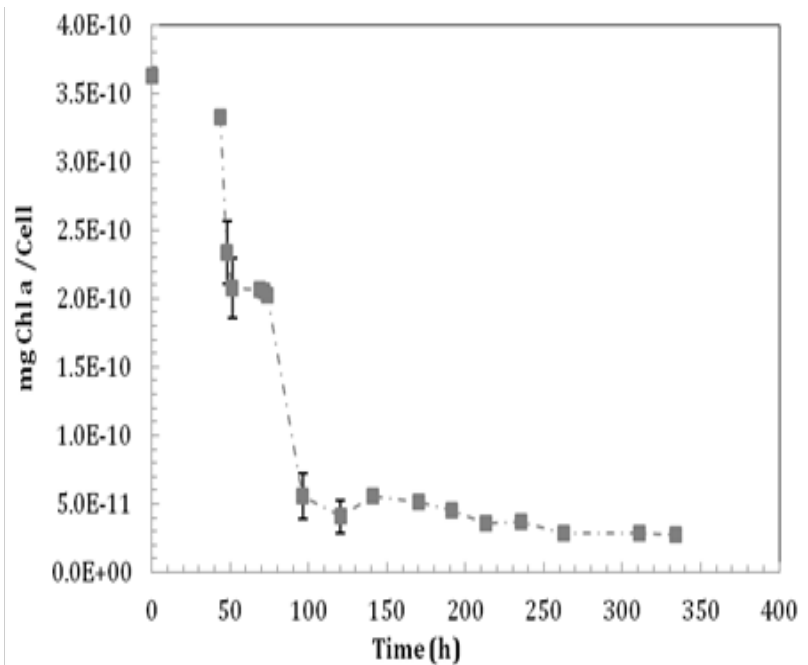

Figure 5 Average cell-chlorophyll a content during C. vulgaris culture.

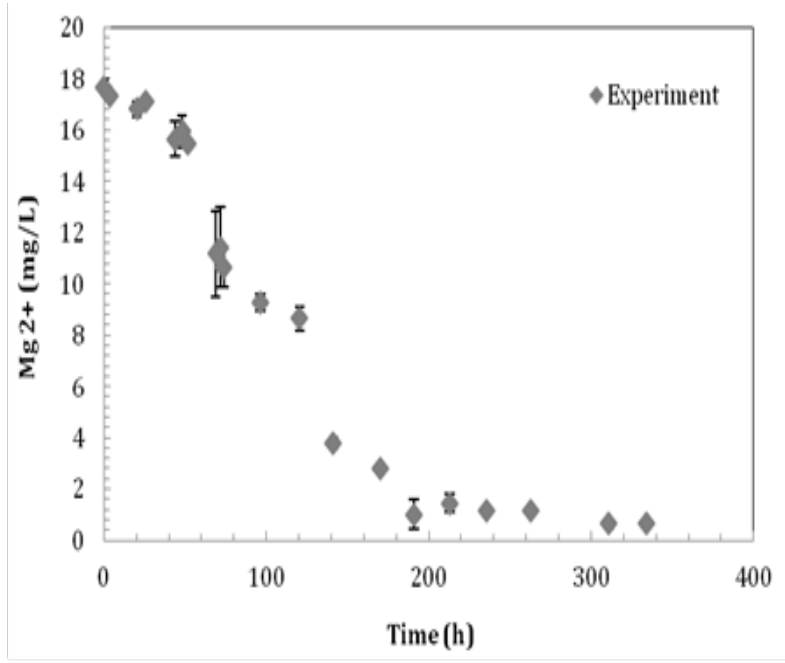

Figure 6 Removal of $\mathrm{Mg}^{2+}$ ions by C. vulgaris from the growth medium.

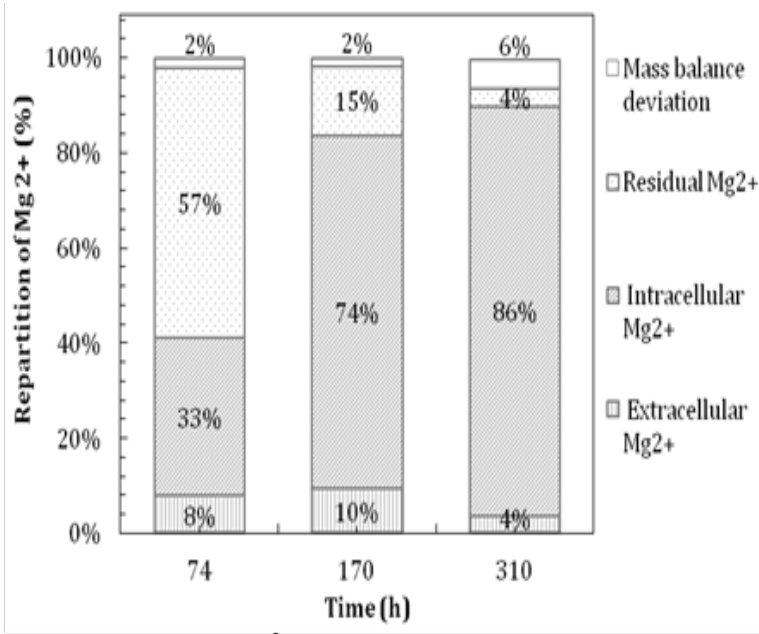

Figure 7 Repartition of $\mathrm{Mg}^{2+}$ ions in the biomass during growth. The mass balance deviation refers to the amount of $\mathrm{Mg}^{2+}$ ions that could not be accounted for. The error bars show the difference in the results observed between the two experiments.

$=$ Compared with our previous publication, ${ }^{11}$ the accumulation of magnesium by algae in mixotrophic culture was lower than that in autotrophic culture. At the end of the experiment (310h), C. vulgaris absorbed on average $3.44 \mathrm{mg}$ of $\mathrm{Mg}^{2+}$ ions per $\mathrm{g}$ of dry biomass whereas in autotrophic photo-bioreactor cultures $(765 \mathrm{~h}), 6.0 \mathrm{mg}$ were absorbed per $g$ of dry cell weight. In terms of volumetric productivity and efficiency of accumulation from the medium, of course the mixotrophic conditions provide and advantage.

It is then effective strategy to use autotrophic followed by heterotrophic conditions to produce more biomass and to maximize $\mathrm{Mg}^{2+}$ ion uptake. As an interpretation, the $\mathrm{Mg}^{2+}$ bioaccumulation mechanism is as a result of a coupling between biochemical reactions and mass transfer. The external transfer of $\mathrm{Mg}^{2+}$ from the solution to the algae depends essentially on the hydrodynamics and the biochemical reactions largely depend on the cells physiology and the growth limitations (light). A greater extent of growth would present a larger surface area though which transfers could occur. 


\section{Model for $\mathrm{Mg}^{2+}$ ion accumulation by $\mathrm{C}$. vulgaris}

The experimental results were plotted versus the predicted model curve (Figure 8). They fitted well with the exponential model for magnesium uptake by $C$. vulgaris confirming its applicability. These results were in good agreement with our previous published work, ${ }^{10}$ where we developed an exponential model for the $\mathrm{Mg}^{2+}$ ion uptake by $C$. vulgaris in shake-flask autotrophic cultures with different initial $\mathrm{Mg}^{2+}$ ion concentrations $(8.9-465 \mathrm{mg} / \mathrm{L})$. Two differences were found with our previous work; ${ }^{10,11}$ firstly $\mathrm{C}_{\text {eq }}$ seems to be negligible and secondly $\mathrm{Mg}^{2+}$ ion uptake starts after a lag time of $45 \mathrm{~h}$ from the start of the experiments. This shows that the majority of the ion is accumulated while growth occurs under heterotrophic conditions. In other words, the exchange surface produced by the greater growth brought about by heterotrophic growth dominated the $\mathrm{Mg}^{2+}$ ion adsorption and absorption phenomena. This model described well the $\mathrm{Mg}^{2+}$ ion uptake by $C$. vulgaris. Future experiments will be performed to explore $\mathrm{Mg}^{2+}$ ion uptake under different glucose and initial $\mathrm{Mg}^{2+}$ ion concentrations and to find suitable explanations for the different behaviors observed in this study.

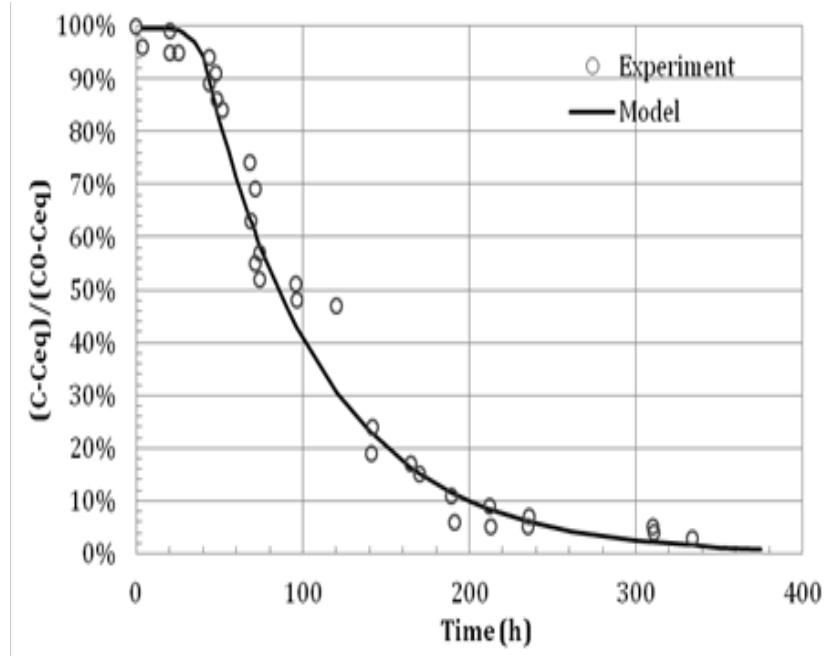

Figure 8 Comparison of model data (solid line) and experimental measurements (circles) of the accumulation mechanism by $C$. vulgaris. The concentrations $\mathrm{C}, \mathrm{C}_{0}$ and $\mathrm{C}_{\mathrm{eq}}$ are the $\mathrm{Mg}^{2+}$ ion concentrations at times: $\mathrm{t}, \mathrm{t} 0$ and at equilibrium respectively.

\section{Conclusion}

The biomass production of $C$. vulgaris under mixotrophic conditions was significantly higher than in autotrophic cultures. The nitrate exhaustion brought about the end of the exponential phase and it coincided with the start of glucose consumption; there was nevertheless no direct evidence of true mixotrophy where glucose and $\mathrm{CO}_{2}$ would be incorporated into the biomass simultaneously. $C$. vulgaris adopted an autotrophic metabolism before the exhaustion of the nitrogen source even in the presence of glucose. The specific growth rate was $0.056 \mathrm{~h}^{-1}$ close to that reported by Perner Nochta et al. ${ }^{21}$ at $0.058 \mathrm{~h}^{-1}$ for the same strain in a batch tubular bioreactor culture. The chlorophyll $\alpha$ was an indicator of photosynthetic activity and was followed during the experiment. Starting with an initial $\mathrm{Mg}^{2+}$ ion concentration of $17.7 \mathrm{mg} / \mathrm{L}$ in the growth medium, C. vulgaris accumulated $3.44 \mathrm{mg}$ of $\mathrm{Mg}$ per $\mathrm{g}$ of dry biomass under mixotrophic growth and $6.0 \mathrm{mg}$ of $\mathrm{Mg}^{2+}$ per $\mathrm{g}$ of dry biomass under autotrophic growth. $\mathrm{Mg}^{2+}$ ion removal by biomass from growth medium was directly related to the cell concentration and physiology. During autotrophy, the cells need magnesium to synthesize chlorophyll for photosynthesis, so they accumulate a larger amount of magnesium. In contrast, during heterotrophic growth less $\mathrm{Mg}^{2+}$ is required by the cells as they switch to using glycolysis and respiration.

The micro-organism showed a preference for autotrophic growth even in the presence of glucose. Later on during the experiment, there was no evidence for mixotrophic growth although this could not be excluded neither. The duplicate experiments were highly reproducible, throughout the entire duration of the experiments (310h) and for all the different parameters measured. This study supported our previous results ${ }^{10,11}$ that $C$. vulgaris is a suitable microorganism for $\mathrm{Mg}^{2+}$ ion uptake and the method first published by Franklin et al. ${ }^{16}$ is applicable for the measurement of $\mathrm{Mg}^{2+}$ ion uptake in C. vulgaris. The experimental data fitted well with the exponential model for $\mathrm{Mg}^{2+}$ ion uptake by $C$. vulgaris cells. The work presented here confirms the application of this model for metal ion sorption in microalgae cultures and the modeling work will be further pursued as in additional experiments under different conditions. This study presents promising results for the development at industrial scale of $C$. vulgaris cultures with high cell production and $\mathrm{Mg}^{2+}$ ion uptake potential.

\section{Acknowledgements}

The authors wish to thank Soliance SAS, the CentraleSupelec Chair for Industrial Biotechnology and the Tunisian Ministry of Research and Higher Education for financial support. In addition, the authors would like to thank Barbara Malinowska and Vincent Butin for their technical assistance with the ion chromatography and atomic absorption analyses. Thanks to Clément Hussenet for his assistance with the glucose measurements. Thanks to Cyril Breton and Thierry Martin for the construction and assembly of various laboratory equipment.

\section{Conflict of interest}

The author declares no conflict of interest.

\section{References}

1. Chen GQ, Chen F. Growing phototrophic cells without light. Biotechnol Lett. 2006;28(9):607-616.

2. Lee YK. Algal Nutrition-Heterotrophic Carbon Nutrition. In: Richmond A, editor. Handbook of Microalgal Culture. 2nd ed. Oxford, UK: Blackwell Publishing; 2004. p. 116-124.

3. Qiao H, Wang G, Zhang X. Isolation and characterization of Chlorella sorokiniana GXNN01 (chlorophyta) with the properties of heterotrophic and microaerobic growth. J Phycol. 2009;45(5):1153-1162.

4. Chen CY, Yeh KL, Aisyah R, et al. Cultivation, photo bioreactor design and harvesting of microalgae for biodiesel production: A critical review. Bioresource Technol. 2011;102:71-81.

5. Ogbonna JC, Ichige E, Tanaka H. Interactions between photoautotrophic and heterotrophic metabolism in photoheterotrophic cultures of Euglena gracilis. Appl Microbiol Biotechnol. 2002;58(4):532-538.

6. Cheirsilp B, Torpee S. Enhanced growth and lipid production of microalgae under mixotrophic culture condition: Effect of light intensity, glucose concentration and fed-batch cultivation. Bioresour Technol. 2012;110:510-516.

7. Liang Y, Sarkany N, Cui Y. Biomass and lipid productivities of Chlorella vulgaris under autotrophic, heterotrophic and mixotrophic growth conditions. Biotechnol Lett. 2009;31(7):1043-1049. 
8. Arunakumara KKIU, Xuecheng Z. Heavy metal bioaccumulation and toxicity with special reference to microalgae. J Ocean Univ China. 2008;7(1):60-64.

9. Kim MH, Chung WT, Lee MK, et al. Kinetics of removing nitrogenous and phosphorus compounds from swine waste by growth of microalga, Spirulina platensis. J Microbiol Biotechnol. 2000;10(4):455-461.

10. Ben Ayed HBA, Taidi B, Ayadi H, et al. Effect of Magnesium ion concentration in autotrophic cultures of Chlorella vulgaris. Algal Res. 2015;9:291-296.

11. Ben Ayed HBA, Taidi B, Ayadi H, et al. Magnesium uptake by the green microalga Chlorella vulgaris in batch cultures. J Microbiol Biotechnol. 2016;26(3):503-510.

12. Jyoti SS, Kumar DR, Kaur BS, et al. Application of Magnesium Sulfate and its nanoparticles for enhanced lipid production by mixotrophic cultivation of algae using biodiesel waste. Energy (Oxford). 2014;78:16-22.

13. Larosière BC, Lopes F, Gonçalves A, et al. Carbon dioxide biofixation by Chlorella vulgaris at different $\mathrm{CO}_{2}$ concentrations and light intensities. Eng Life Sci. 2014;14(5):509-519.

14. Vernon LP, Seely GR. The Chlorophylls. 1st ed. New York: Academic press; 1966. $436 \mathrm{p}$.

15. Porra R. The assay of Chlorophylls a and b converted to their respective Magnesium Rhodochlorin derivatives by extraction from recalcitrant algal cells with aqueous alkaline Methanol: Prevention of allomeization with reductant. Biochim Biophys Bioenerg. 1990;1015(3):493-502.

16. Franklin NM, Stauber JL, Markich SJ, et al. pH-Dependent toxicity of copper and uranium to a tropical freshwater alga (Chlorella sp.). Aquat Toxicol. 2000;48(2-3):275-289.

17. Ma M, Zhu W, Wang Z, et al. Accumulation, assimilation and growth inhibition of Copper on freshwater alga (Scenedesmus subspicatus 86.81 SAG) in the presence of EDTA and fulvic Acid. Aquat Toxicol. 2003;63(3):221-228.
18. Rocha JM, Garcia JE, Henriques MH. Growth aspects of the marine microalga Nannochloropsis gaditana. Biomol Eng. 2003;20(4-6):237-242.

19. Ting YP, Prince IG, Lawson F. Uptake of Cadmium and Zinc by the alga Chlorella vulgaris: II. Multi-Ion Situation. Biotechnol Bioeng. 1991;37(5):445-455.

20. Wood M, Everroad C. Measuring growth rates in microalgal cultures. In: Anderson RAA editor. Algal Culturing techniques. USA: Elseiver academic press; 2005. p. 269-286.

21. Nochta, IP, Lucumi A, Posten C. Photoautotrophic cell and tissue culture in a tubular photobioreactor. Eng Life Sci. 2007;7(2):127-135.

22. Lee YK, Ding SY, Hoe CH, et al. Mixotrophic growth of Chlorella sorokiniana in outdoor enclosed photobioreactor. J Appl Phycol. 1966;8(2):163-169.

23. Illman A, Scragg A, Shales S. Increase in Chlorella strains calorific values when grown in low Nitrogen medium. Enzyme And Microbial Technology. 2000;27(8):631-635.

24. Li Y, Horsman M, Wang B, et al. Effects of Nitrogen sources on cell growth and lipid accumulation of green alga Neochloris oleoabundans. Appl Microbiol Biotechnol. 2008;81(4):629-636.

25. Kong W, Song H, Cao Y, et al. The characteristics of biomass production, lipid accumulation and chlorophyll biosynthesis of Chlorella vulgaris under mixotrophic cultivation. African Journal of Biotechnology. 2011;10(55):11620-11630.

26. Dombek KM, Ingram LO. Magnesium limitation and its role in apparent toxicity of Ethanol during yeast fermentation. Appl Environ Microbiol. 1998;52(5):975-981. 